\title{
Cancer Prevention and Control: Where are the Kids?
}

\author{
E. Robert Burns
}

Published online: 10 November 2013

(C) Springer Science+Business Media New York 2013

The Journal of Cancer Education May 2012 supplement \#2 (27) entitled "Workforce Gaps and Opportunities in Cancer Prevention \& Control" focused on the expanding need for a larger and more efficient cancer prevention workforce. Topics discussed ranged from the number of physician and nurse oncologists to communication and funding problems. In the "recommendations" sections of the papers in this special issue, no mention of cancer education/prevention opportunities for school-age children was made. Yet this is the age group that begins to make lifestyle choices such as tobacco and/or tanning booth use. Without proper health science information regarding these practices, youngsters are at risk of making uninformed and therefore poor lifestyle decisions. School-age children should be a major target for cancer prevention education. For example, in the 2012 Report of the Surgeon General on "Preventing Tobacco Use Among Youth and Young Adults" (http://www.cdc.gov/tobacco), it was stated that "tobacco use is a pediatric epidemic, around the world as well as in the United States - with nearly all tobacco use beginning in childhood and adolescence." This editorial suggests a way to provide cancer prevention education to school-age children.

The kids are there.

There are about 90 million children attending public and private PreK-12 schools in the USA. They are a captive audience waiting to be educated.

Young children are very interested in learning about human organ biology and disease.

Biology is the most popular of school-age children's interest in science. The topics of interest ranked in descending

E. R. Burns $(\bowtie)$

Department of Neurobiology and Developmental Sciences, College

of Medicine, University of Arkansas for Medical Sciences, 4301

West Markham St., Little Rock, AR 72205, USA

e-mail: burnsbob@uams.edu order were: first - anatomy and physiology; secondscience and medicine; third-genetics and reproduction; fourth-behavior, neurobiology, and the mind; fifthman and animal relationships; and sixth-biotechnology. For example, $68 \%$ of the grade K-8 children ranked anatomy and physiology, and sickness and medicine as their primary interests. Regarding their primary interests, only $11 \%$ listed genetics and reproduction and $1.4 \%$ listed biotechnology [1].

The teachers of these interested students, however, usually are not trained in science/health science education leaving it untaught.

Two quotes from middle school students are revealing: "A lot of my teachers tell me that smoking causes lung cancer but none of them can tell me how this happens" and "Skin cancer can be prevented - I think. We haven't really discussed that in school" [2].

The problem of teachers being poorly prepared to teach science has been documented [3]. In summary, students will not be able to learn science if their teachers do not have adequate knowledge on the science they teach. Teachers need better preservice and inservice training in science to deepen their knowledge on the science content of the curriculum. Proper training of teachers in the health sciences, especially cancer prevention education, obviously is needed.

It has been suggested that future advances made in improving the nation's health will not result from spectacular biomedical breakthroughs, but from advances in personally initiated actions that are directly influenced by the individual's health-related attitudes, beliefs, and knowledge through school-based health science education. It has been recommended that there be increased in-service and preservice professional development opportunities and incentives for persons responsible for teaching health education. Preservice professional preparation of all teachers should include 
teaching to the National Health Education Standards, and health education concepts should be included on state teachers' examinations [4].

There is a model program that provides health science education, including cancer prevention education, to PreK12 teachers.

In 1991, the University of Arkansas for Medical Sciences (UAMS) made a formal commitment to PreK-12 science education with the initiation of its Partners in Health Sciences (PIHS) program. PIHS has offered professional development opportunities in the health sciences to PreK-12 teachers in both in-service and preservice arenas at the statewide level. As of the end of August 2013, 22,040 participants have consumed 79,012 h of professional development training in 119 different health science topics, many of which were in the realm of cancer biology/cancer prevention education, taught by 202 different faculty individuals in 241 workshops (minimum of $3 \mathrm{~h}$ to a maximum of $24 \mathrm{~h}$ over 3 days). The general approach is a mini-medical school format where gradeappropriate levels of normal functional anatomy at the cell, tissue, and organ levels of biological organization are followed by exposure to appropriate pathological conditions. Most workshops ended with a presentation of clinical content. Teachers and some school nurses have participated from all 75 counties in the state. With significant extramural funding, the teachers came to the UAMS campus for the workshops with travel and housing costs reimbursed. With less funding, the trainer travels to local communities to offer the workshops, and teachers attend from surrounding towns and counties. In this way, since 2002 through August 2013, 134 professional development workshops have been held in 31 different communities in all geographical regions of the state. The topics presented to K-12 teachers were biology of cancer, healthy lungs and gums, and healthy skin. In addition, healthy hearts and lungs workshops were presented exclusively to PreK teachers. This educational outreach uses a "train and equip" method, i.e., during the community workshop, participants receive face-to-face, interactive training and gain hands-on experience with items that are a component of a resource kit given to each participant for eventual use with their students. The resource kit contains a profusely illustrated syllabus, a CD copy of all images used in the workshop, and a set of materials and items of equipment - the average cost of a resource kit is $\$ 300$. As documented in long-term follow-up studies, the training sessions coupled with the use and gift of the resource kits foster the transference of the workshop training into new learning opportunities and activities for students when the participant returns to her/his community school classroom [5-9].
The train-and-equip approach to providing professional development to teachers contains a significant sustainability factor. Because the participants exit the training with a resource kit in hand instead of these items returning to the medical center for reuse, one newly trained and equipped teacher can replicate the new curriculum and its hands-on activities annually for the duration of her/his professional career, thereby impacting thousands of students with only one initial investment in the training and the resource kit.

The UAMS-PIHS outreach model is an example of how any medical sciences or university campus could develop an infrastructure and partnerships involving multiple school districts, educational cooperatives, math + science centers, and colleges of education to provide both in-service and preservice professional development in any science topic. UAMS is the only medical school in the state of Arkansas, and this fostered the development of a statewide outreach effort. In the absence of federal extramural funding (Science Education Partnership Award from the NCRR-NIH), state funding has been obtained annually from the AR Cancer Coalition, the AR Department of Health, and the AR Department of Human Services-Division of Child Care and Early Childhood Education.

\section{References}

1. Baram-Tsabari A, Yarder A (2007) Interest in biology: a developmental shift characterized using self-generated questions. Amer Biol Teach 69:532-540

2. CDC (2013) National health education standards and its 2nd ed national health education standards - achieving excellence, updated by CDC 2/27/13. http://www.cdc.gov/healthyyouth/sher/standards/. Accessed 19 Oct 2013

3. Duschl RA, Schweingruber HA, Shouse AW (2007) Taking science to school: learning and teaching science in grades K-8. National Academies, Washington

4. The Gallup Organization (1994) Values and opinions of comprehensive school health education in US public schools: adolescents, parents and school district administrators. Am Cancer Society, Atlanta

5. Burns ER (2002) Anatomy of a successful K-12 educational outreach program in the health sciences - eleven years experience at one medical sciences campus. Anat Rec (New Anatomist) 269:181-193

6. Burns ER (2008) Use of the published Lance Armstrong cancer story to teach health science content to high school students. Amer Biology Teacher 70:17-22

7. Burns ER (2008) Functional anatomy of the cardiovascular system: professional development for preK-3 teachers using a "train and equip" method results in learning opportunities for students. Anat Sci Ed 1:119-125

8. Burns ER (2012) Healthy lungs: cancer education for middle school teachers using a "train and equip" method. J Cancer Educ 27(1):179185

9. Burns ER, Lindsey MS (2004) Cancer education and cancer prevention education for K-12 teachers and students. J Cancer Educ 19:105-110 